\title{
Quality of life in people with Type 2 diabetes; a study in a multi-ethnic clinical trial population
}

\author{
SHAIFALI KULKARNI, PAUL WELSH, MYZOON ALI, * JOHN R PETRIE* ON BEHALF OF THE \\ VICCTA-DIABETES COLLABORATORS * *
}

\begin{abstract}
Background: The long-term burden of self-management in type 2 diabetes can impact quality of life.

Aims: To examine associations between demographic and clinical factors, anxiety/depression and perception of health in people with type 2 diabetes.

Methods: Retrospective analyses of anonymised data from completed clinical trials provided by the diabetes subsection of Virtual International Cardiovascular and Cognitive Trials Archive (VICCTA). Data on demographics, polypharmacy, $\mathrm{HbA}_{1 \mathrm{c}}$, anxiety/depression (EQ-5D-3L) and perception of health (EQ-5D-3L VAS) were extracted. Regression analyses explored associations amongst polypharmacy, $\mathrm{HbA}_{1 \mathrm{c}}$ and quality of life (anxiety/depression and health perception) at baseline.

Results: In 2783 participants with type 2 diabetes (median age 66 years (IQR 61-70), $n=1,595$ (57\%) male), female sex and Caucasian/European ethnicity were each associated with increased anxiety/depression and lower EQ-5D-3L VAS scores. Following adjustment for covariates, each additional prescribed medication was associated with increased anxiety/depression: OR $1.09(95 \% \mathrm{Cl} 1.04$ to $1.14 ; \mathrm{p}<0.001)$ and lower VAS scores: $\mathrm{B}=-1.06(95 \% \mathrm{Cl}-1.37$ to $-0.75, \mathrm{p}<0.001))$.

Conclusion: Demographic factors and polypharmacy are associated with anxiety/depression and lower health perception. Br J Diabetes 2021;21:210-215
\end{abstract}

Key words: anxiety, depression, diabetes, quality of life

\section{Introduction}

Type 2 diabetes comprises $90 \%$ of diabetes cases worldwide. ${ }^{1}$ People with type 2 diabetes experience a high burden of self-

${ }^{*} \mathrm{MA}$ and JRP are joint senior authors.

**See Acknowledgements.

Institute of Cardiovascular and Medical Sciences, University of Glasgow, Glasgow, UK

Address for correspondence: Dr Myzoon Ali Virtual Trials Archives Coordinator, M0.07 Office Block, Queen Elizabeth University Hospital, University of Glasgow, Glasgow, G51 4TF, UK

E-mail: myzoon.ali@glasgow.ac.uk.

https://doi.org/10.15277/bjd.2021.315 management of their condition and are at an increased risk of depression and lower quality of life.2,3 Given the impact on quality of life and the high prevalence of mental health conditions in people with type 2 diabetes, there is a need to better understand these associations. ${ }^{4}$

Several demographic and clinical factors may affect quality of life and prevalence of anxiety/depression in people with type 2 diabetes: for example, depression is more likely to occur in younger women with diabetes. ${ }^{5}$ There is conflicting evidence regarding the role of ethnicity, with one study showing that African Americans with type 2 diabetes were less likely to report depressive symptoms compared with other ethnicities, while another showed no link. ${ }^{6,7}$ Another study of men with type 2 diabetes aged $70-89$ years found that the risk of depression was greatest immediately after diagnosis and towards the end of life. ${ }^{8} \mathrm{~A}$ previous meta-analysis also reported a link between obesity, depression and type 2 diabetes. ${ }^{9}$

Type 2 diabetes is a challenging condition due to associations with other morbidities and complications; this often results in polypharmacy, defined as taking five or more medications. ${ }^{10,11} \mathrm{~A}$ higher medication burden is twice as likely in people with diabetes and co-existing mental health conditions, including anxiety/depression. ${ }^{12}$ While an increased medication burden has been shown to adversely affect quality of life, the potential link between anxiety/depression and polypharmacy is under-researched. ${ }^{13}$

Evidence is somewhat conflicting on the association between glycaemic control and anxiety/depression. However, lower $\mathrm{HbA}_{1 c}$ levels, reflecting better metabolic control, have been associated with higher quality of life. ${ }^{14}$

Validated predictors that can be used in the clinic to identify people with type 2 diabetes at risk of anxiety/depression are lacking. One study found that mental health conditions in people with diabetes were only identified by health professionals when symptoms were severe. ${ }^{15}$ For the present analysis, access to archived data from existing high-quality studies provided an opportunity to further explore these associations. We sought to identify demographic and clinical risk factors, including polypharmacy, associated with a higher risk of anxiety/depression and lower quality of life to inform the management and support of people with type 2 diabetes.

\section{Methods}

Transparency and openness

In this article we report how we determined all data exclusions and measures included in the study. Data can be made available 
by contacting viccta@glasgow.ac.uk. We analysed data using IBM SPSS Statistics version 26.

\section{Design}

We conducted retrospective analyses of fully anonymised, placebo group, randomised controlled trial data from the diabetes subsection of VICCTA (www.virtualtrialsarchives.org/viccta). VICCTA is a collaborative venture that coordinates access to datasets from trials and registries to allow further clinical research.

\section{Data extraction}

VICCTA-Diabetes typically contains people with diabetes, a glycated haemoglobin level of $7.5 \%$ or more, or an admission blood glucose $>11.0 \mathrm{mmol} / \mathrm{L}$, aged $18-79$ years, and can include people with cardiovascular disease or risk factors for cardiovascular disease; selected body mass index (BMI) criteria include BMI $\geq 25 \mathrm{~kg} / \mathrm{m}^{2}(>23$ $\mathrm{kg} / \mathrm{m}^{2}$ for Asians) and $\leq 45 \mathrm{~kg} / \mathrm{m}^{2}$ (with stable body weight $( \pm 5 \%$ ) for 3 months), and receiving a stable dose of antihyperglycaemic medication for $\geq 3$ months prior to screening, maintenance of prior diet and exercise habits during the study, and women of child-bearing potential using two medically approved methods of contraception and continued use during the course of the trial.

\section{Data access and ethical approval}

The Steering Committee governing VICCTA-Diabetes approved the project proposal and granted access to the dataset. VICCTA holds institutional ethical approval (University of Glasgow, MVLS Ethics).

\section{Data extraction}

We selected key demographic variables considered to be associated with anxiety/depression and overall health perception following a review of the literature. We extracted data on age, sex, BMI, ethnicity, duration of type 2 diabetes, age at onset, self-reported data on dependency for activities of daily living (ADLs) and medical history. The number of prescribed medications, $\mathrm{HbA}_{1 \mathrm{c}}$ measures, anxiety/depression and overall perception of health at baseline were also extracted.

The self-reported European Quality of Life (EQ-5D-3L) domain score was used to define the presence or absence of anxiety/ depression. We defined "no anxiety/depression" as a score of 1 (not anxious/depressed) and "anxiety/depression" as a score of 2 or 3 on the EQ-5D-3L anxiety/depression domain.

We defined the individual perception of health using the selfreported Visual Analogue Scale (VAS) score. A score of 100 translated to the "best health you can imagine" and a score of 0 translated to the "worst health you can imagine".

\section{Statistical analysis}

We described the population using summary statistics; continuous variables using medians and IQRs and categorical variables using frequencies and percentages (\%). We examined univariable associations among age, sex, ethnicity, BMl, type 2 diabetes duration, polypharmacy, $\mathrm{HbA}_{1 \mathrm{c}}$, anxiety/depression and VAS scores in regression analyses. In multivariable analyses we included the variables found to be statistically significant in univariable analyses $(p<0.05)$. Models were checked for approximate linearity and adjusted for age, sex, ethnicity, BMI and diabetes duration. Logistic regression analyses were reported as odds ratios (OR) and $95 \%$ confidence intervals $(95 \% \mathrm{Cl})$ while linear regression models were reported using unstandardised beta coefficients (B) and standardised beta coefficients ( $\beta$ ). We excluded participants with missing data from the relevant analyses.

\section{Results}

\section{Study population characteristics}

The analysis population comprised people with a diagnosis of type 2 diabetes mellitus at 30 years of age or older, an age of at least 55 years at the time of study entry and a history of major macrovascular or microvascular disease or at least one other risk factor for vascular disease.

Data were available from 2,783 people with type 2 diabetes (57\% male, median age 66 years, median duration of diabetes

Table 1 Characteristics of the study population

\begin{tabular}{|c|c|c|}
\hline Variable & Number & $\%$ \\
\hline \multicolumn{3}{|l|}{ Sex } \\
\hline Men & 1,595 & 57 \\
\hline Women & 1,188 & 43 \\
\hline \multicolumn{3}{|l|}{ Ethnicity } \\
\hline Caucasian/European & 1,667 & 60 \\
\hline Chinese & 842 & 30 \\
\hline South Asian or South-East Asian & 217 & 7.8 \\
\hline Others & 57 & 2.0 \\
\hline \multicolumn{3}{|l|}{ Number of concurrent medications } \\
\hline 0 & 44 & 1.6 \\
\hline $1-3$ & 1,240 & 45 \\
\hline $4-6$ & 1,198 & 43 \\
\hline $7-10$ & 300 & 11 \\
\hline$>10$ & 1 & 0 \\
\hline \multicolumn{3}{|l|}{ Smoking status } \\
\hline Current smokers & 169 & 6.1 \\
\hline Ex-smokers & 758 & 27 \\
\hline Non-smokers & 1,856 & 67 \\
\hline \multicolumn{3}{|l|}{ Presence of comorbidities } \\
\hline Prior stroke & 259 & 9.3 \\
\hline Myocardial infarction & 327 & 12 \\
\hline Chronic ischaemic heart disease & 174 & 3.7 \\
\hline Transient ischaemic attack & 115 & 4.1 \\
\hline Heart failure & 78 & 2.8 \\
\hline Atrial fibrillation & 151 & 5.4 \\
\hline Hypertension & 1,946 & 70 \\
\hline Leg ulcers & 41 & 1.5 \\
\hline Retinopathy & 606 & 21.8 \\
\hline \multicolumn{3}{|l|}{ EQ-5D-3L anxiety/depression score } \\
\hline 1 (not anxious/depressed) & 1,988 & 72 \\
\hline 2 (moderately anxious /depressed) & 745 & 27 \\
\hline \multirow[t]{2}{*}{3 (extremely anxious/depressed) } & 37 & 1.3 \\
\hline & Median & IQR \\
\hline Age (years) & 66 & $61-70$ \\
\hline Diabetes duration (years) & 7 & $3-11$ \\
\hline Age of T2D onset (years) & 58 & $52-64$ \\
\hline BMI $\left(\mathrm{kg} / \mathrm{m}^{2}\right)$ & 27.6 & $24.7-31.1$ \\
\hline $\mathrm{HbA}_{1 \mathrm{c}}(\mathrm{mmol} / \mathrm{mol})$ & 55 & $48-66$ \\
\hline VAS score according to EQ-5D-3L & 80 & $70-90$ \\
\hline
\end{tabular}


7 years and median BMI $27.6 \mathrm{~kg} / \mathrm{m}^{2}$ ). Caucasian/European ethnicity was most prevalent (60\%). The prevalence of current smoking was $6.1 \%$ and median $\mathrm{HbA} \mathrm{Ac}_{\mathrm{c}}$ level was $55 \mathrm{mmol} / \mathrm{mol}$. $28 \%$ of participants had anxiety/depression (defined as some or extreme problems on the EQ-5D-3L) and the median VAS score was 80 (Table 1).

\section{Factors associated with anxiety/depression}

In univariable analysis, female sex was significantly associated with an increased prevalence of anxiety/depression $(p<0.001)$. Chinese ethnicity $(p=0.046)$, older age $(p=0.007)$ and a lower BMI $(p=0.040)$ were each significantly associated with lower odds of anxiety/ depression (Figure 1).

In multivariable analysis, South/South-East Asian versus Caucasian/European ethnicity (OR, $0.67 ; 95 \% \mathrm{Cl} 0.47$ to 0.95 ; $\mathrm{p}=0.026)$, Chinese versus Caucasian/European ethnicity (OR 0.75; $95 \% \mathrm{Cl} 0.61$ to $0.93 ; \mathrm{p}=0.009$ ) and older age (OR $0.98 ; 95 \% \mathrm{Cl}$ 0.97 to $0.99 ; p=0.004$ ) were each significantly associated with lower odds of anxiety/depression. Female sex was significantly associated with increased odds of anxiety/depression (OR 2.03; $95 \% \mathrm{Cl} 1.71$ to $2.41 ; p<0.001)$.

We then examined polypharmacy. In univariable analysis $(n=2,770)$, polypharmacy was significantly associated with increased anxiety/depression (OR 1.09; 95\% Cl 1.04 to 1.13; $\mathrm{p}<0.001$ ) (Table 2).
Multivariable analyses ( $n=2,713)$, adjusting for covariates, revealed that polypharmacy remained significantly associated with increased anxiety/depression (OR 1.09; $95 \% \mathrm{Cl} 1.04$ to 1.14; $\mathrm{p}<0.001)$. Within this model, older age (OR $0.98 ; 95 \% \mathrm{Cl} 0.97$ to 0.99; $p=0.003$ ), Chinese versus Caucasian/European ethnicity (OR $0.79 ; 95 \% \mathrm{Cl} 0.64$ to $0.99 ; \mathrm{p}=0.037)$ and South/South-East Asian versus Caucasian/European ethnicity (OR $0.67 ; 95 \% \mathrm{Cl} 0.47$ to $0.95 ; p=0.024$ ) were each significantly associated with decreased anxiety/depression. Female sex was significantly associated with increased anxiety/depression (OR 2.05; 95\% Cl 1.72 to 2.43; $\mathrm{p}<0.001$ ) (Table 3).

There was no association between dependency for ADLs or $\mathrm{HbA}_{1 \mathrm{c}}$ levels $(n=2,761)$ with anxiety/depression (Figure 1, Table 2$)$.

\section{Factors associated with overall perception of health}

In univariable analysis $(n=2,770)$, polypharmacy was significantly associated with lower VAS scores $(B=-1.40 ; 95 \% \mathrm{Cl}-1.70$ to $-1.10, p<0.001$ ) (Table 2). In multivariable analyses $(n=2,713)$, following adjustment for covariates, polypharmacy remained significantly associated with lower VAS scores $(B=-1.06,95 \% \mathrm{Cl}-1.37$ to $-0.75, p<0.001)$. Within this model, Chinese versus Caucasian/European ethnicity $(B=3.73,95 \% \mathrm{Cl} 2.30$ to 5.16 , $\mathrm{p}<0.001)$ and South/South-East Asian versus Caucasian/European ethnicity $(B=3.77,95 \% \mathrm{Cl} 1.52$ to $6.02, p=0.001)$ were each

Table 2 Summary of baseline characteristics and design of studies included in this review

\begin{tabular}{|c|c|c|c|c|c|c|c|c|c|c|c|}
\hline \multirow[t]{3}{*}{ Independent variable } & \multicolumn{5}{|c|}{ Anxiety/depression } & \multicolumn{6}{|c|}{ VAS score } \\
\hline & \multirow[t]{2}{*}{$\mathrm{N}$} & \multirow[t]{2}{*}{ OR } & \multicolumn{2}{|c|}{$95 \% \mathrm{Cl}$} & \multirow[t]{2}{*}{$P$ value } & \multirow[t]{2}{*}{ N } & \multirow[t]{2}{*}{ B } & \multicolumn{2}{|c|}{$95 \% \mathrm{Cl}$} & \multirow[t]{2}{*}{$\beta$} & \multirow[t]{2}{*}{ P value } \\
\hline & & & LL & UL & & & & LL & UL & & \\
\hline No of medications $(+1)$ & 2,770 & 1.09 & 1.04 & 1.13 & $<0.001$ & 2,771 & -1.40 & -1.70 & -1.10 & -0.17 & $<0.001$ \\
\hline $\mathrm{HbA}_{1 \mathrm{C}}$ (+1 percentage point) & 2,761 & 1.00 & 0.94 & 1.05 & 0.924 & 2,762 & 0.10 & -0.28 & 0.48 & 0.01 & 0.616 \\
\hline
\end{tabular}

Odds ratios (OR), 95\% confidence intervals ( $\mathrm{Cl}$ ) and $\mathrm{P}$ values were obtained by logistic regression. Unstandardised beta coefficients (B), $95 \%$ confidence intervals (CI), standardised beta coefficients $(\beta)$ and $P$ values were obtained by linear regression.

$\mathrm{HbA}_{1 \mathrm{c}}$, glycated haemoglobin $\mathrm{A}_{1}$; $\mathrm{LL}$, lower limit; ULL, upper limit; VAS, Visual Analogue Scale.

Table 3 Summary of baseline characteristics and design of studies included in this review

\begin{tabular}{|c|c|c|c|c|c|c|c|c|c|c|c|}
\hline \multirow[t]{3}{*}{ Independent variable } & \multicolumn{5}{|c|}{ Anxiety/depression } & \multicolumn{6}{|c|}{ VAS score } \\
\hline & \multirow[t]{2}{*}{$\mathrm{N}$} & \multirow[t]{2}{*}{ OR } & \multicolumn{2}{|c|}{$95 \% \mathrm{Cl}$} & \multirow{2}{*}{$P$ value } & \multirow[t]{2}{*}{$\mathrm{N}$} & \multirow[t]{2}{*}{ B } & \multicolumn{2}{|c|}{$95 \% \mathrm{Cl}$} & \multirow[t]{2}{*}{$\beta$} & \multirow[t]{2}{*}{$P$ value } \\
\hline & & & LL & UL & & & & $\mathrm{LL}$ & UL & & \\
\hline Age & & 0.98 & 0.97 & 0.99 & 0.003 & & -0.06 & -0.15 & 0.03 & -0.03 & 0.181 \\
\hline BMI & & 0.99 & 0.97 & 1.01 & 0.412 & & -0.33 & -0.46 & -0.20 & -0.11 & $<0.001$ \\
\hline Diabetes duration & & 1.01 & 0.99 & 1.02 & 0.856 & & -0.04 & -0.13 & 0.05 & -0.02 & 0.410 \\
\hline \multicolumn{12}{|l|}{ Ethnicity } \\
\hline Caucasian/ European & & & Ref & & & & & Ref & & & \\
\hline Chinese & & 0.79 & 0.64 & 0.99 & 0.037 & & 3.73 & 2.30 & 5.16 & 0.11 & $<0.001$ \\
\hline South Asian or South-East Asian & & 0.67 & 0.47 & 0.95 & 0.024 & & 3.77 & 1.52 & 6.02 & 0.07 & 0.001 \\
\hline
\end{tabular}


Figure 1. Proportion of people with anxiety/depression according to sex, ethnicity and dependency for activities of daily living

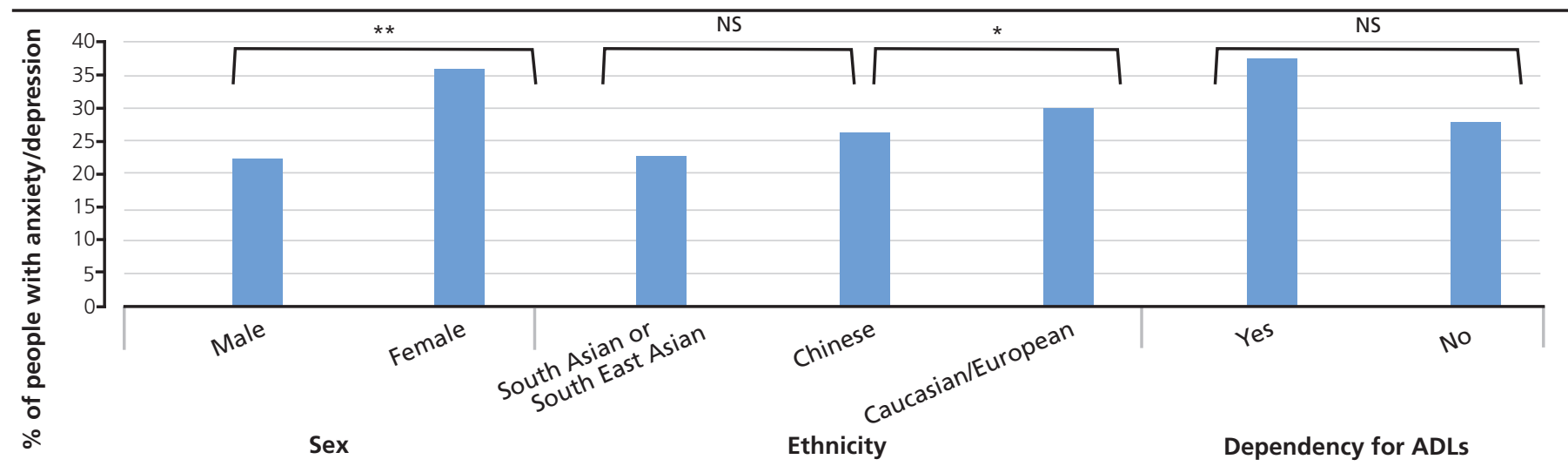

Note: $n=2,770$ for sex; $n=2,713$ for ethnicity; $n=2,770$ for dependency for ADLs.

$P$ values for sex and dependency for $A D L s$ derived from $X 2$ test of association. $P$ values for ethnicity derived from logistic regression. ${ }^{*} p<0.05 ;{ }^{*}{ }^{*} p<0.001$.

ADLs, activities of daily living; NS, not significant.

significantly associated with higher VAS scores. A higher BMI $(B=-0.33,95 \% \mathrm{Cl}-0.46$ to $-0.20, p<0.001)$ and female sex $(B=-1.35,95 \% \mathrm{Cl}-2.50$ to $-0.20, p=0.021)$ were each significantly associated with lower VAS scores (Table 3).

$\mathrm{HbA}_{1 \mathrm{c}}$ levels were not associated with VAS scores in univariable analysis $(\mathrm{n}=2,761)$ (Table 2).

\section{Discussion}

\section{Main findings}

In this analysis of pooled data from the placebo groups of diabetes clinical trials, female sex and Caucasian/European ethnicity were each associated with increased anxiety/depression and a lower perception of health. Increased medication burden was also associated with increased anxiety/depression and lower perception of health.

\section{Strengths and limitations of this study}

Strengths of this study include a moderate sample size and a multi-ethnic population; although derived from participants in clinical trials, many characteristics were similar to those of people with type 2 diabetes seen in clinical practice. ${ }^{16}$ Anonymised clinical trial data were of high quality, near complete and standardised according to operational definitions. Moreover, the 3-point EQ-5D-3L score is a convenient method of detecting anxiety/ depression and has been used in other studies including participants with type 2 diabetes. ${ }^{17-19}$ One study, albeit from participants without diabetes, found that respondents with diagnosed depression reported more problems on all components of the EQ-5D score than participants with no medical conditions..$^{20}$

In terms of limitations, average glycaemic control was closer to target than in most clinic populations. While the EQ-5D-3L score has its benefits, it only has moderate sensitivity, a "ceiling effect" ${ }^{17}$ and may introduce self-reporting bias.

Nevertheless, the associations we observed with anxiety/ depression aligned with our findings on quality of life.
Our retrospective analysis of an existing dataset meant we were unable to examine the impact of variables such as stressful life events, fear of hypoglycaemia, health literacy and diabetes distress. Finally, we did not adjust for multiplicity in these exploratory analyses.21

\section{Interpretation of findings in relation to previously published work}

Our study showed that $28 \%$ of participants reported having anxiety/depression using the EQ-5D-3L scale. Studies using other self-reporting measures ${ }^{22,23}$ and clinician-led measures ${ }^{24-26}$ show similar figures.

Our observation of sex differences in anxiety/depression supports findings in previous studies. 5,27 Lower EQ-5D scores both in women with type 2 diabetes and in the general population have also been previously reported. ${ }^{28,29}$

In addition, there have been previous reports that Caucasian participants with type 2 diabetes are at increased risk of depressive symptoms..$^{30}$ Moreover, there is evidence, albeit from populations without diabetes, that people of non-Caucasian ethnicities are less likely to seek help regarding mental health than Caucasians. ${ }^{31}$ Non-Caucasian/European participants may therefore have been less likely to self-report anxiety/depression.

We observed that, for each additional prescribed medication, the risk of anxiety/depression increased by approximately $9 \%$. This is in keeping with results from previous research from other populations..$^{12}$ Number of prescribed medications may be an indicator of disease severity (ie, a marker of more severe/advanced type 2 diabetes with associated anxiety/depression and lower quality of life). However, clinicians should be aware of the negative impacts of polypharmacy and, where possible, review and/or minimise the number of prescribed medications as this may reduce anxiety/depression and improve quality of life.

Our observation of a lack of association between $\mathrm{HbA}_{1 c}$ and anxiety/depression differs from previous research. ${ }^{27,32}$ Although 


\section{Key messages}

- In a multi-ethnic clinical trial population with type 2 diabetes, female sex, Caucasian/European and polypharmacy were each associated with increased anxiety/depression and lower health perception.

- These findings could contribute to development of future interventions to better manage and support people with type 2 diabetes.

our sample size was moderate, we acknowledge that there may not have been sufficient statistical power given the relative insensitivity of the anxiety/depression scoring on the EQ-5D-3L (a 3-point ordinal scale).

\section{Implications for future research, policy and practice}

Our findings have clinical relevance: anxiety and depression can be a barrier to self-management for people with type 2 diabetes and heighten the risk of severe and life-changing microvascular and macrovascular complications. In addition, diabetes distress (defined as unease occurring due to the self-managing nature of diabetes and the future possibility of complications) is associated with higher $\mathrm{HbA}_{1 c} .{ }^{27,33,34}$ Increased awareness of mental health conditions among specific high-risk subpopulations of people with type 2 diabetes, such as women and Caucasians, may contribute to improving outcomes. ${ }^{35}$

\section{Conclusion}

Female sex, Caucasian ethnicity and polypharmacy are associated with increased anxiety/depression in people with type 2 diabetes. These findings could contribute to development of future targeted interventions to better manage and support mental health and quality of life in people with type 2 diabetes.

Acknowledgements The authors would like to thank the VICCTADiabetes Steering Committee who commented on the project proposal.

$* *$ VICCTA-Diabetes Steering Committee: Azmil Abdul-Rahim, John Chalmers, Barry Davis, Mattias Herz, Kennedy R Lees, Klas Malmberg, John Petrie, Naveed Sattar and Mark Woodward.

\section{Conflict of interest None.}

Funding Access to VICCTA-Diabetes was funded by the BSC (MedSci) intercalated degree programme at the University of Glasgow.

Contributorship SK: conceptualisation, methodology, data analysis, investigation, visualisation and writing of the article. PW: supervision of data analysis. MA: conceptualisation, data curation, methodology, supervision and writing of the article. JRP: conceptualisation, methodology, supervision and writing of the article.

\section{References}

1. World Health Organisation. 10 facts on diabetes. https://www.who.int/features/factfiles/diabetes/en/ (accessed 5 August 2021).

2. Schram M, Baan C, Pouwer F. Depression and quality of life in patients with diabetes: a systematic review from the European Depression in Diabetes

(EDID) Research Consortium. Curr Diabetes Rev 2009;5:112-19. https://doi.org/10.2174/157339909788166828

3. Polonsky WH. Emotional and quality-of-life aspects of diabetes management. Curr Diabetes Rep 2002;2:153-9. https://doi.org/10.1007/s11892002-0075-5

4. Wylie TAF, Shah $\mathrm{C}$, Connor $\mathrm{R}$, et al. Transforming mental well-being for people with diabetes: research recommendations from Diabetes UK's 2019 Diabetes and Mental Well-Being Workshop. Diabet Med 2019;36:15328. https://doi.org/10.1111/dme.14048

5. Zhao W, Chen Y, Lin M, et al. Association between diabetes and depression: Sex and age differences. Public Health 2006;120:696-704. https://doi.org/10.1016/j.puhe.2006.04.012

6. De Groot M, Pinkerman B, Wagner J, et al. Depression treatment and satisfaction in a multicultural sample of type 1 and type 2 diabetic patients. Diabetes Care 2006;29:549-53. https://doi.org/10.2337/diacare.29.03.06. dc05-1396

7. Golden SH, Lee HB, Schreiner PJ, et al. Depression and type 2 diabetes mellitus: The multiethnic study of atherosclerosis. Psychosomatic Med 2007; 69:529-36. https://doi.org/10.1097/PSY.0b013e3180f61c5c

8. Almeida OP, McCaul K, Hankey GJ, et al. Duration of diabetes and its association with depression in later life: The Health in Men Study (HIMS). Maturitas 2016;86:3-9. https://doi.org/10.1016/j.maturitas.2016.01.003

9. Luppino FS, De Wit LM, Bouvy PF, et al. Overweight, obesity, and depression: A systematic review and meta-analysis of longitudinal studies. Arch Gen Psychiatry 2010;67:220-9. https://doi.org/10.1001/archgenpsychiatry.2010.2

10. Dobrică EC, Găman MA, Cozma MA, et al. Polypharmacy in type 2 diabetes mellitus: Insights from an internal medicine department. Medicina (Lithuania) 2019;55:1-10. https://doi.org/10.3390/medicina55080436

11. Masnoon N, Shakib S, Kalisch-Ellett L, et al. What is polypharmacy? A systematic review of definitions. BMC Geriatrics 2017;17:1-10. https://doi.org/10.1186/s12877-017-0621-2

12. Alwhaibi M, Balkhi B, Alhawassi TM, et al. Polypharmacy among patients with diabetes: a cross-sectional retrospective study in a tertiary hospital in Saudi Arabia. BMJ Open 2018;8:1-8. https://doi.org/10.1136/bmjopen2017-020852

13. Austin RP. Polypharmacy as a risk factor in the treatment of type 2 diabetes. Diabetes Spectrum 2006;19:13-16. https://doi.org/10.2337/diaspect.19.1.13

14. Lau CY, Qureshi AK, Scott SG. Association between glycaemic control and quality of life in diabetes mellitus. J Postgrad Med 2004;50:189-93.

15. Poulsen KM, Pachana NA, McDermott BM. Health professionals' detection of depression and anxiety in their patients with diabetes: the influence of patient, illness and psychological factors. J Health Psycho/ 2016;21:156675. https://doi.org/10.1177/1359105314559618

16. Aguilar-Salinas CA, Monroy OV, Gómez-Pérez FJ, et al. Characteristics of patients with type 2 diabetes in México: results from a large populationbased nationwide survey. Diabetes Care 2003;26:2021-6. https://doi.org/ 10.2337/diacare.26.7.2021

17. Janssen MF, Lubetkin El, Sekhobo JP, et al. The use of the EQ-5D preference-based health status measure in adults with type 2 diabetes mellitus. Diabet Med 2011;28:395-413. https://doi.org/10.1111/j.1464-5491. 2010.03136.x

18. Solli O, Stavem K, Kristiansen I. Health-related quality of life in diabetes: the associations of complications with EQ-5D scores. Health and Quality of Life Outcomes 2010;8:18. https://doi.org/10.1186/1477-7525-8-18

19. Abedini MR, Bijari B, Miri Z, et al. The quality of life of the patients with diabetes type 2 using EQ-5D-5L in Birjand. Health and Quality of Life Outcomes 2020;18:18. https://doi.org/10.1186/S12955-020-1277-8

20. Johnson JA, Pickard AS. Comparison of the EQ-5D and SF-12 health surveys in a general population survey in Alberta, Canada. Medical Care 2000;38:115-21.

21. Chen SY, Feng Z, Yi X. A general introduction to adjustment for multiple comparisons. J Thoracic Dis 2017;9:1725-9. https://doi.org/10.21037/ jtd.2017.05.34

22. Collins MM, Corcoran P, Perry IJ. Anxiety and depression symptoms in patients with diabetes. Diabet Med 2009;26:153-61. https://doi.org/10.1111/J.1464-5491.2008.02648.X

23. Lloyd CE, Dyert PH, Barnett AH. Prevalence of symptoms of depression and anxiety in a diabetes clinic population. Diabet Med 2000;17:198-202. 
https://doi.org/10.1046/j.1464-5491.2000.00260.x

24. Rajput R, Gehlawat P, Gehlan D, et al. Prevalence and predictors of depression and anxiety in patients of diabetes mellitus in a tertiary care center. Indian J Endocrinol Metab 2016;20:746. https://doi.org/10.4103/22308210.192924

25. Gavard JA, Lustman PJ, Clouse RE. Prevalence of depression in adults with diabetes: an epidemiological evaluation. Diabetes Care 1993;16:1167-78. https://doi.org/10.2337/DIACARE.16.8.1167

26. Ali N, Jyotsna VP, Kumar N, et al. Prevalence of depression among type 2 diabetes compared to healthy non diabetic controls. J Assoc Physicians India 2013;61:619-21.

27. Larijani B, Khoram M, Bayat S, et al. Association between depression and diabetes. German J Psychiatry 2004;7:62-5.

28. Parik P, Patel V. Health-related quality of life of patients with type 2 diabetes mellitus at a tertiary care hospital in India using Eq 5D 5L. Indian J Endocrinol Metab 2019;23:407-11. https://doi.org/10.4103/ijem.IJEM_29_19

29. Janssen MF, Szende A, Cabases J, et al. Population norms for the EQ-5D-3L: a cross-country analysis of population surveys for 20 countries. Eur $\mathrm{J}$ Health Econ 2019;20:205-16. https://doi.org/10.1007/s10198-018-0955-5
30. González-Castro TB, Escobar-Chan YM, Fresan A, et al. Higher risk of depression in individuals with type 2 diabetes and obesity: results of a metaanalysis. J Health Psychol 2019;26:1404-19. https://doi.org/10.1177/ 1359105319876326

31. Bailey RK, Mokonogho J, Kumar A. Racial and ethnic differences in depression: current perspectives. Neuropsychiatr Dis Treat 2019;15:603-09. https://doi.org/10.2147/NDT.S128584

32. Schmitt A, Bendig $E$, Baumeister $H$, et al. Associations of depression and diabetes distress with self-management behavior and glycemic control. Health Psycho/ 2020;40:113-14. https://doi.org/10.1037/hea0001037

33. Fisher L, Mullan JT, Arean $P$, et al. Diabetes distress but not clinical depression or depressive symptoms is associated with glycemic control in both crosssectional and longitudinal analyses. Diabetes Care 2010;33:23-8. https://doi.org/10.2337/dc09-1238

34. Polonsky WH, Fisher L, Earles J, et al. Assessing psychosocial distress in diabetes: development of the Diabetes Distress Scale. Diabetes Care 2005;28:626-31. https://doi.org/10.2337/diacare.28.3.626

35. Bădescu SV, Tătaru C, Kobylinska L, et al. The association between diabetes mellitus and depression. J Med Life 2016;9:120-5. 